\title{
A FRAMEWORK FOR DATA COLLECTION IN FACILITY PROGRAMMING: THE SUBJECT-OBJECT APPROACH
}

\section{LUBOMIR POPOV, FRANKLIN GOZA}

\begin{abstract}
:
This study presents a framework designed to enable facility programming scholars to more easily handle the extremely large amounts of information they typically utilize, to guide the development of their research designs and procedures, and to suggest process structure. This framework's development was informed by both Activity Theory and Systems Theory and synthesizes knowledge about the most important aspects and layers of the sociospatial realm, articulating those analytical clusters that can be used as guides for developing programmatic research designs. The framework created is general enough to cover a wide variety of building types and programming situations. It is also flexible enough to be modified in multiple ways, including the possible addition of vast amounts of supplementary detail, to custom fit a specific facility programming project. The idea of creating a flexible guiding framework is based on the notion that in each programmatic situation content must be updated and aligned with specific organizational realities. Although very important to have theoretical support and shared research experience, each facility programming project is different and requires the adaptation of existing knowledge, as well as methodological erudition and proficiency to deal with the idiosyncrasies that emerge; all of which are possible with this framework. As such, this framework is foundational and pliable enough for further adaptation.
\end{abstract}

The essence of this framework is reflected in by a matrix consisting of vertical and horizontal axes. This matrix emphasizes those facets most important to exploring sociospatial structures and relationships. The horizontal axis of the framework is based on an activity model that consists of agents, their goals, activities, necessary conditions, and the built environment. The vertical axis includes three levels or scales for analyzing the social realm: organization, groups and individuals. Each matrix cell provides information that can be used to develop guidelines for developing customized programmatic research designs and instruments. Each of the resulting 15 cells in this matrix is elaborated in detail. We believe that this framework will make significant contributions to the area of facility programming by providing an easily accessible and useful tool to area experts.

\section{Keywords:}

facility programming, theory of facility programming, methodology of programming research, framework for data collection

JEL Classification: R00, Q53, R58

\section{Authors:}

LUBOMIR POPOV, Bowling Green State University, United States, Email: Lspopov@bgsu.edu FRANKLIN GOZA, University of Wisconsin-Whitewater, United States, Email: gozaf@uww.edu 


\section{Citation:}

LUBOMIR POPOV, FRANKLIN GOZA (2019). A Framework for Data Collection in Facility Programming: The Subject-Object Approach . International Journal of Social Sciences, Vol. VIII(2), pp. 108-133., 10.20472/SS.2019.8.2.007 


\section{A Framework for Data Collection in Facility Programming: The Subject- Object Approach}

\section{Introduction}

This study's goal is to present a framework designed to assist with the collection of facility programming information, especially among those who use facility programming to study building users and stakeholders. This is the second part of our project focusing on the development of a framework designed to guide the process of information collection in facility programming. Our initial study Philosophical Foundations and Metatheoretical Considerations for Creating Frameworks to Collect Facility Programming Information (Popov \& Goza, 2018) presented the philosophical foundations for the creation of this framework. The framework we here is conceived as a wide-ranging and flexible guide for the development of project-specific research instruments. We interpret framework to mean a way to organize information about a social phenomenon and as a way to systematically present a class or type of phenomena for the purpose of guiding research on the specific phenomenon examined (Jabareen, 2009; Popov \& Goza, 2018). Consequently, this framework will be presented as a theoretical arrangement for organizing relevant components and interrelationships.

The idea of a multipurpose framework does not imply that a preconceived "cookie-cutter" must be imposed on every situation studied (Popov \& Goza, 2018). Rather, we suggest that what is needed is an abstract and inclusive conceptual structure, one flexible enough to be further elaborated when applied to specific building types and programming situations. The level of abstraction we develop is prompted by the notions of "sensitizing concepts" (Glaser \& Strauss, 1967) and "thinking units" (Lofland \& Lofland, 1995). The "sensitizing concepts approach" was created by Herbert Blumer (1954) and further elaborated by other authors working in the realm of Grounded Theory methodology. Essentially, those scholars argue that researchers create concepts that will increase their awareness and guide them during either the theorization or research processes. The "thinking units approach" (Lofland \& Lofland, 1995) is based on the notion that even when we are reluctant to impose a preconceived conceptual framework on the social reality studied, we still need prompts to begin the investigation and to be certain that basic aspects of the phenomenon studied are not omitted.

As mentioned before in Popov and Goza (2018), facility programming is about examining building users and stakeholders for the purpose of developing design requirements and for generating the information required in order to make design decisions (Cherry, 1999; Duerk, 1993; Hershberger, 2015; Lang \& Moleski, 2010; Preiser, 1993). Such programming involves a significant amount of inquiry which must be conducted with sound research methods (Popov \& Goza, 2018). Although there are different paradigmatic views about the role and the process of preparing research designs, it is our belief that research requires thorough planning and that a well-designed examination should guide both data collection and analysis (Popov \& Goza, 2018).

Our prior study reviewed (Popov \& Goza, 2018) 40 years of relevant theoretical resources in the field of facility programming. This lengthy review revealed only a limited number of studies with 
frameworks designed for the purpose of collecting programming information. We also reviewed social science literature in a number of fields in search of frameworks that could be adapted to serve scholars working on programming research (Popov \& Goza, 2018). Although some earlier publications provided interesting insights, not a single study was found that was designed to serve as a framework for guiding research design development or to assist those working in the field of facility programming (Popov \& Goza, 2018).

\section{Methodological Considerations}

In the first part of this project (Popov \& Goza, 2018) we elaborated key methodological considerations and guidelines for building conceptual frameworks in the field of programming research. We ultimately selected two approaches to guide our research, Systems Theory and Activity Theory (Popov \& Goza, 2016). Using these approaches, we developed foundational ideas which serve as the guidelines for building our conceptual framework for programming research (Popov \& Goza, 2018). Those guidelines are now used to develop more specific ideas and to develop one possible version of the many alternatives that could emerge as a result of using these general guidelines to collect data.

As earlier mentioned, this work draws on both Systems Theory (Bausch, 2001; Bailey, 1994; 2001; Bausch, 2001) and Activity Theory (Bedny \& Karwowski, 2007; Kaptelinin, Kuutti \& Bannon, 1995), as well as the subject-object vision of the social world (Lektorskii, 1990). The subject-object model is a very abstract presentation of social reality drawn from the Activity Theory perspective (Lektorskii, 1990). We translated or concretized this very abstract model to the point where the concept of subject is narrowed and further specified in terms of (social) agents, actors, users, and stakeholders (Popov \& Goza, 2018). Our use of the term concretization means taking an abstract concept and "translating" it into more concrete terms. Note, we are not talking about measurement, but rather about translating a very abstract model into a more specific one.

From an Activity Theory perspective (Lektorskii, 1990; Popov \& Goza, 2016), the first step in concretizing the subject-object model is to introduce activity as a linking mechanism. Thus, we go to the subject-activity-object relationship. These general terms can now be translated into the more specific terms agents-activity-built environment in order to adapt them to facility programming. This is the first step towards further concretization using Activity Theory.

Activity Theory provides a particular understanding of the functioning of the social world and the sociospatial reality, including sociospatial interactions and relationships that link together all components into one holistic entity (Luhmann, 1995; 2012; Popov \& Goza, 2018; Prenkert, 2006). There are a number of assumptions based on this general model of sociospatial interactions. First, agents can be analyzed and interpreted in terms of activity (Engestrom, Miettinen \& Punamaki, 1999), while activity can be analyzed in terms of agents (organizations, groups, individuals), processes, and objects (built environment) (Bedny \& Karwowski, 2007; Holt \& Morris, 1993). Following these assumptions, we developed a number of additional conceptualizations. From an Activity Theory point of view, human beings can be seen as social agents and conscious actors that formulate goals (Lektorskii, 1990). Agents achieve their goals in the process of an 
activity or a series of activities. In this process, they experience a need for particular conditions (Lektorskii, 1990). Some of these conditions are provided by the built environment. In this way, we can develop a chain of relationships and components that constitute an Activity Theory model of sociospatial interactions: agents/users—user goals-activities for achieving these goalsnecessary conditions for performing these activities, and the-built environment, which provides these conditions (Popov \& Goza, 2018; Wade, 1977).

The agent-built environment model can be viewed as a "horizontal" cross section of sociospatial reality and a horizontal axis of the framework for collecting programming information. We refer to this as horizontal because all section components should be at the same level of abstraction and analysis. Following the postulates of Systems Theory, we also envisage a "vertical" section of organization for agents and sociospatial phenomena. The vertical section consists of several levels that progress from larger social entities and phenomena to smaller ones. This way of thinking stems from a number of sources pertaining to the social and management sciences (Bedny \& Karwowski, 2007; Brannick, Levine \& Morgeson, 2007; Fararo, 2001; Hendrick \& Kleiner, 2005; Luhmann, 1995; 2012; Wilson et al., 2012), as well as environment and behavior studies (Wapner, 1987).

From a systems perspective, we can conceptualize the agents-activity-built environment model as a system of articulated components among a hierarchy of levels (Borkowski, 2015; Jackson, 2000; Tobach, 1999; Wapner, 1987). According to social science systems analysis (Bailey, 1994; 2001; Fararo, 2001), each of the components in the horizontal section can be developed and concretized in layers or levels, based on the hierarchy of levels. Thus, the Agents component can be articulated in terms of organizational, group, and individual levels, each one progressively smaller in scale (Blackler, 1993; Jackson, 2000). So, the Agent component will have a different nature and content at each level of analysis. Similarly, the Activity component will have different content at each level (e.g., different processes, structures, and regularities (Popov \& Goza, 2016; Wapner, 1987)). In this way, the emerging framework is a matrix organized into three different and juxtaposed layers of the agent-built environment continuum. Each component (or cell of the matrix) has its own nature and properties, depending on its function in the sociospatial continuum, as well as its level of functioning in the social system (Popov \& Goza, 2018).

There is one more dimension of social reality that must be considered-culture. Culture is intertwined with social entities at each scale or level of existence and its presentation in a twodimensional diagram is a challenge (Lektorskii, 1990). We conceptualize culture as a quality of the social; a way of doing things or of performing an activity (Rapoport, 2005), a way of thinking, organizing, and managing (Hofstede, Hofstede \& Minkov, 2010). Culture is also a mechanism for enforcing values and norms, social reproduction, and a dimension or attribute of activity (Engestrom, Miettinen \& Punamaki, 1999; Lektorskii, 1990). From an activity perspective, culture shapes social entities, activity patterns, and artificial environment. However, this approach attempts to present culture as intertwined in the description of each component of the framework, not as a separate layer or entity. 


\section{The Framework: An Overview}

The framework we present below is a generic one, one designed to serve many types of organizations, including: corporations, civic, leisure and recreation, and not-for-profits. We have tried to select the most common features pertinent to these organizations in relation to programmatic analysis. The framework is also influenced by the design of formal organizations (Burton, et al., 2006; Cummings \& Worley, 2008; Holt \& Morris, 1993). This is done to introduce more structure into the process of facility programming for informal organizations. We believe that this framework will make significant contributions to the area of facility programming for organizations by providing an easily accessible and useful tool to area experts.

The idea of creating a guiding framework is based on the notion that in every programmatic situation the content must be updated and aligned with specific organizational realities. Although fully aware of diverse programmatic situations, we believe in the necessity of a guiding document that will eliminate the need to "reinvent the wheel" for each project. For those reasons, the framework needs to be understood and interpreted as foundational for further adaptation. The selected categories and their contents should be viewed as illustrative of the approximate types of information that should be collected. However, depending on the specific project situation, programmers will make their own selection regarding which types and forms of information need to be collected.

The table below presents the sensitizing and guiding concepts formatted by organizational level (Borkowski, 2009; McLean, 2006). Each level starts with the Agent entity and moves towards Built Environment. This approach allows for a better explication of interactions and relationships within the sociospatial system. Also, organizing the social reality at the higher levels somewhat helps define the lower levels (Banathy, 1996). Without understanding the nature and the influence of the higher levels, it will be difficult to comprehend and redesign the lower levels. This is why the framework starts with the highest level of organization and proceeds to the lowest level. The horizontal axis of the framework starts with the Agent and proceeds towards Built Environment, showing the direction of research moving from Agent to Built Environment. However, the process is cyclical and we have considered the necessity for feedback and for cycling through the research process several times until programmers are able to collect and align all required information. That is why we have formally introduced a feedback loop that begins with Built Environment, as using that information suggests how to fine-tune the research of the other framework components and again returns to the Agents. 


\begin{tabular}{|c|c|c|c|c|c|}
\hline $\begin{array}{l}\text { THE } \\
\text { SOCIOSPATIAL } \\
\text { REALITY }\end{array}$ & 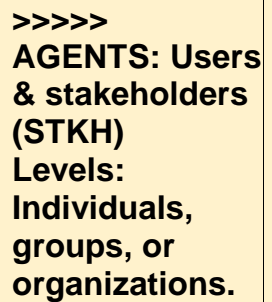 & $\begin{array}{l}\text { >>>> } \\
\text { GOALS: } \\
\text { Link agents to } \\
\text { activities by } \\
\text { presupposing } \\
\text { types of } \\
\text { actions. }\end{array}$ & $\begin{array}{l}\text { AC>>> } \\
\text { Major linking } \\
\text { mechanism. } \\
\text { Relate agents } \\
\text { to environment. }\end{array}$ & $\begin{array}{l}\text { >>>> } \\
\text { NECESSARY } \\
\text { CONDITIONS: } \\
\text { Relate activities } \\
\text { and agents to } \\
\text { environment. }\end{array}$ & $\begin{array}{l}\text { BUILT } \\
\text { ENVIRONMENT: } \\
\text { Provides } \\
\text { conditions, } \\
\text { instrumental } \\
\text { features, } \\
\text { resources. }\end{array}$ \\
\hline \multirow[t]{2}{*}{$\begin{array}{l}\text { LEVEL: } \\
\text { Organization } \\
\text { (and its social } \\
\text { environment) }\end{array}$} & $\begin{array}{l}\text { > research loop } \\
\text { Social } \\
\text { environment, } \\
\text { market, } \\
\text { competition. } \\
\text { The organization } \\
\text { as a whole. }\end{array}$ & $\begin{array}{l}\text { >>>>> } \\
\text { Vision, mission, } \\
\text { goals, strategy, } \\
\text { and policies. } \\
\text { (presuppose } \\
\text { instrumental } \\
\text { activities) }\end{array}$ & $\begin{array}{l}\text { O>>> } \\
\text { Organizational } \\
\text { processes, } \\
\text { operations, and } \\
\text { activity systems: } \\
\text { flows of mate- } \\
\text { rials, energy, } \\
\text { and information. }\end{array}$ & $\begin{array}{l}\text { P>>> } \\
\text { Necessary } \\
\text { conditions for } \\
\text { the flows and } \\
\text { activity systems. }\end{array}$ & $\begin{array}{l}\text { Design and } \\
\text { planning } \\
\text { requirements/ } \\
\text { Spatial } \\
\text { organization of } \\
\text { the whole } \\
\text { building. }\end{array}$ \\
\hline & $\begin{array}{l}<\text { feedback loop } \\
\text { STKH action for } \\
\text { feedback and } \\
\text { negotiation. }\end{array}$ & $\begin{array}{l}\text { C<<<< } \\
\text { Conflict with } \\
\text { STKH functions } \\
\text { and goals }\end{array}$ & $\begin{array}{l}<<<<< \\
\text { Undesirable } \\
\text { effects on STKH } \\
\text { activities }\end{array}$ & $\begin{array}{l}<<<< \\
\text { Undesirable } \\
\text { effects and } \\
\text { consequences } \\
\text { for STKH. }\end{array}$ & $\begin{array}{l}<\text { feedback loop } \\
\text { Spatial effects } \\
\text { and } \\
\text { consequences for } \\
\text { STKH. }\end{array}$ \\
\hline \multirow[t]{2}{*}{$\begin{array}{l}\text { LEVEL: } \\
\text { Group/Team/ } \\
\text { Department }\end{array}$} & $\begin{array}{l}\text { >research loop } \\
\text { Departments } \\
\text { and } \\
\text { teams/groups. } \\
\text { Populations of } \\
\text { behavior } \\
\text { settings. }\end{array}$ & $\begin{array}{l}\text { >>>>> } \\
\text { Department, } \\
\text { group, or unit } \\
\text { goals: a) related } \\
\text { to the } \\
\text { organization, b) } \\
\text { for sustaining } \\
\text { the unit. }\end{array}$ & $\begin{array}{l}\text { >>>> } \\
\text { Operations and } \\
\text { activity systems, } \\
\text { behavior } \\
\text { patterns, } \\
\text { patterns of social } \\
\text { interaction. }\end{array}$ & $\begin{array}{l}\text { >>>>> } \\
\text { Necessary } \\
\text { conditions for } \\
\text { teamwork, social } \\
\text { interaction and } \\
\text { social needs of } \\
\text { individuals. }\end{array}$ & $\begin{array}{l}\text { Design } \\
\text { requirements of } \\
\text { the group/team. }\end{array}$ \\
\hline & $\begin{array}{l}<\text { feedback loop } \\
\text { STKH action for } \\
\text { feedback and } \\
\text { negotiation. }\end{array}$ & $\begin{array}{l}\text { Cor<< } \\
\text { Conflict with } \\
\text { SKH functions } \\
\text { and goals }\end{array}$ & $\begin{array}{l}<<<<< \\
\text { Undesirable } \\
\text { effects on STKH } \\
\text { activities }\end{array}$ & $\begin{array}{l}<<<< \\
\text { Undesirable } \\
\text { effects on STKH, } \\
\text { creating new } \\
\text { problems. }\end{array}$ & $\begin{array}{l}\text { <feedback loop } \\
\text { Spatial effects } \\
\text { and } \\
\text { consequences for } \\
\text { stakeholders. }\end{array}$ \\
\hline \multirow[t]{2}{*}{$\begin{array}{l}\text { LEVEL: } \\
\text { Individual }\end{array}$} & $\begin{array}{l}\text { >research loop } \\
\text { Organism, } \\
\text { psyche, social } \\
\text { status; values, } \\
\text { culture. }\end{array}$ & $\begin{array}{l}\text { >>>>> Goals } \\
\text { and objectives: } \\
\text { life goals, } \\
\text { professional } \\
\text { goals, work } \\
\text { objectives. }\end{array}$ & $\begin{array}{l}\text { >>>> Activity } \\
\text { and behavior } \\
\text { patterns, } \\
\text { personal } \\
\text { experience. }\end{array}$ & $\begin{array}{l}\text { Necessary } \\
\text { conditions for } \\
\text { the individuals in } \\
\text { their activities. }\end{array}$ & $\begin{array}{l}\text { Design } \\
\text { requirements. } \\
\text { Spatial } \\
\text { organization of } \\
\text { environment for } \\
\text { the individual. } \\
\end{array}$ \\
\hline & $\begin{array}{l}<\text { feedback loop } \\
\text { STKH action for } \\
\text { feedback and } \\
\text { negotiation. }\end{array}$ & $\begin{array}{l}<<<<< \\
\text { Conflict with } \\
\text { STKH functions } \\
\text { and goals }\end{array}$ & $\begin{array}{l}<<<<< \\
\text { Undesirable } \\
\text { effects on STKH } \\
\text { activities }\end{array}$ & $\begin{array}{l}\text { U<<< } \\
\text { Undesirable } \\
\text { effects on STKH. }\end{array}$ & $\begin{array}{l}\text { < feedback loop } \\
\text { Spatial effects \& } \\
\text { consequences for } \\
\text { stakeholders. }\end{array}$ \\
\hline
\end{tabular}

Table 1. The general framework for collecting programming information

\section{$4 \quad$ The Organizational Level}

As its name suggests, the organizational level includes the organization and its environment, although our starting point is the organizational environment. This level provides insights into the overall nature of the organization, as well as the environmental factors that shape it (Borkowski, 2009; McLean, 2006). We limit this discussion to those select aspects of the organization that have sociospatial implications and must be considered in the programmatic process. 


\subsection{The Organization as an Economic and Social Subject/Agent}

The organization is the starting point for most programmatic investigations. In many cases, when considering a remodeling or building project, programmatic research should begin with the organization that will be housed by the new spatial structure. The life span of a new building and the resources needed for it are typically projected over a thirty-year period. This includes mortgages, maintenance, remodeling, utilities, and so forth. It is prudent to foresee the organization and its trajectory several years into the future (Romm, 1994). Although extremely challenging, it is prudent to at least attempt to do this. For us, this is the core rationale for research-based programming action. Adversaries of research-based programming might dispute such an approach, but at this time, reasonable planning and programmatic actions still make economic sense considering that programming fees are currently less than one quarter of one percent of the cost of the new building.

A facility project that involves tremendous cost requires numerous reviews and updates to organizational plans. In all cases, in order to program the building, it is necessary to engage in some form of organizational (re)design (Davis \& Szigetti, 1979). Although this presupposes additional resources, in the long run this might prove to be more cost-efficient and productive from an organizational point of view (Romm, 1994).

At this level of research and analysis, the organization is seen as one entity functioning within a specific environment. Following systems theory (Popov \& Goza, 2018), the environment may be viewed as an external layer of the system that strongly influences the structuring of the inside levels and its components. Accordingly, it is important to examine the environment in order to understand and redesign the system. One of the main problems, however, is how to define the boundaries of the environment so that the programmatic study doesn't spread endlessly and that it carefully manages time, budget, and intellectual resources (Popov \& Goza, 2018).

Understanding the organizational environment includes a careful review of numerous aspects, including: society, culture, emerging trends, markets, customers, patrons, serviced populations, competition, new technologies, workforce trends, and availability of resources (Burke, 2014; Cummings \& Worley 2008; Freeman et al., 2010). Proper utilization of this information is required to make the correct organizational decisions. This information is also the foundation for updating the vision, mission, and goal structure of the organization in the ensuing stages of organizational design required by facility programming (Burke, 2014; Cummings \& Worley 2008). Programmers will need to acquire such information about the organizational environment either from existing sources or their own research.

This discussion of the organizational environment is a good place to investigate stakeholders. Stakeholders may be categorized both by type and strength of relationship to the organization (Freeman et al., 2010; Stanford, 2007). We view stakeholders as layers, beginning with society at large, followed by a number of related social institutions, local community, clients, customers, patrons, and in general, people serviced by the organization or who will have some type of contact with it. A preliminary investigation of organizational stakeholders will assure that all affected or related parties will be consulted and their interests balanced regarding the consequences of upcoming projects (Safwat, 2015; Stanford, 2007). 
The organization as a (social) agent has its own nature and identity. Understanding these is very important to correctly conducting programmatic investigations and for providing architectural designers with background information required for decision making. Relatedly, organizational culture (Cameron \& Quinn, 2011; Hofstede, Hofstede \& Minkov, 2010; Šikýř, Gorokhova \& Šafránková, 2019) must also be considered. We interpret this as a system of values, norms, rules and regulations, behavior patterns, and simply put, ways of doing things. Culture is all-pervasive, distributed, and embodied at various levels within components of the organization and the framework we propose. Presenting culture and cultural issues in different formats is justified because of the difficulty in separating the cultural and the social. We will use a hybrid approach to do this, discussing organizational culture issues when we present the most important categories of the framework.

Organizational culture usually refers to the upper and holistic levels of analysis (Cameron \& Quinn, 2011; Hofstede, Hofstede \& Minkov, 2010), although this does not preclude analyzing the specifics of each department, team or group. Corporate or organizational culture, in most cases, is a generalization about the overall climate and decision-making system that define action at the subordinate levels (Cameron \& Quinn, 2011; Hofstede, Hofstede \& Minkov, 2010). Programmers should be interested in the institutionalized and practically displayed values, norms, and regulations. These are not only predictors for corporate decision making, but they also provide both programmers and architects with background information for understanding organizational functioning at all levels. The facility project is an opportunity for the organization to reassess its culture and align it with the new social and economic realities (environment). This task is larger than the facility program process by itself and it leads to major management consulting interventions and organizational actions. However, missing this component might render the whole programmatic project inadequate and might negatively impact the integrity of programmatic research at the teleological, activity, and needs levels.

\subsection{The Goals/Teleology of the Organization}

The goal (teleological) structure defines the social action and behavior of social entities, guiding their strategies, approaches, and activities. Teleology is emphasized by praxiological approaches to social and economic action used as the starting point for selecting desired ends. Understanding the organizational goal structure is the foundation for planning future action and activities for achieving these desired ends. Teleological decisions are strongly influenced by understanding the organizational environment. It is important to research the teleological structure in order to successfully review and update (or redesign) the activity systems of the organization (Burke, 2014; Burton et al., 2006; Cummings \& Worley, 2008). This information will guide not only the organizational consultants/designers, but also architectural designers when they conceptualize their project and search for artistic expression that will best communicate the desired image and brand message of the organization. It is very common that architects search for the most important message to help define the organization and programmers can assist them with this.

Organizations should have their current teleological system on file. The programmatic team has to review it to determine its adequacy for the immediate future and its long-term relevancy to the organization. When talking about teleological categories, we need to reflect on organizational 
mission, vision, goals, and strategies. We will consider policies, procedures, rules, programs, and resources later when we discuss organizational activities (Burke, 2014; Burton et al., 2006).

The organizational mission guides the development of other teleological categories, but because of its generality, its operationalization can turn in several directions. For example, there is a difference when a social organization decides to pursue the mission of education for disadvantaged groups versus the narrower mission of continuing education for the unemployed. The choice of mission will presuppose the activity systems and programs that the organization will devise and operate. Programmers need to be cautious when working on the corporate mission as this could affect the company's image and various types of public relations.

The proper explication or redesign of the teleological categories is important for making programmatic decisions at the subsequent levels of organization and activity systems. This might affect programmatic decisions about customization or flexibility of spaces and structures, concerns with constraints and restrictions, and the prioritization of requirements and resources. Errors and shortcomings at this stage might negatively affect the consecutive programmatic action and design decision making.

\subsection{Activities}

Activity Theory suggests that organizational processes and activity systems are the core of the design program and that they should focus on business processes (in business parlance) and/or activity systems (in social science parlance) that are consistent with organizational goals and strategies, as well as logistical support issues (Popov \& Goza, 2016; 2018;). From an Activity Theory perspective, we need to first examine the macro units, their relationships and their interactions (Blackler, 1993; Holt \& Morris, 1993; Tobach, 1999). As such, it is important to understand flows of information, energy, and mass/materiality, which in turn lead to the formulation of major considerations about the organization of space (Becker, Kugeler \& Rosemann, 2003; Keuning, 2007).

The delineation and demarcation of processes and activities at the scale of the whole organization will allow us to break down the organizational design problem into smaller parts that are manageable in both research and design actions (Kuutti, 1999). By assigning relative or temporary autonomy of the business processes and activity systems, the programmatic team can focus its resources on a detailed understanding of the lowest organizational level. This is important because the immediate sociospatial interactions are most intensive at the team/group and individual levels.

When delineating and differentiating various activity systems/business processes, it is possible to think about eventual departmentalization as a method for managing organizational complexity (Burke, 2014; Cummings \& Worley, 2008). Too much autonomy and separation might impede the organization, while too little analytical differentiation would preclude both a detailed design and indepth analysis. The challenge is to find the middle ground that allows for both in-depth analysis and the interconnection of the organizational components into one whole. However, this will remain as a fieldwork problem for programming teams and need to be decided on a case-by-case basis. 


\subsection{Necessary Conditions}

At this level of analysis, necessary conditions are conceptualized in relation to the major business processes and activity systems, as well as the interaction and flows among them. One way to look at this is to see the organization as one business process, with flows of information, energy, and materiality. The various processes and activity systems also can be viewed regarding their inputs and outputs, thus conceptualizing a number of aspects or categories of necessary conditions for the proper functioning of these organizational subsystems (Blackler, 1993; Blackler, Crump \& Mcdonald, 2000; Holt \& Morris, 1993; Tobach, 1999). At the organizational level of analysis, the holistic views of upper and middle management, as well as those of the analytical personnel are very important. The organization of activity systems depends very strongly on the overall perspective and vision about how processes and resources can be configured to prevent mutual impediments and to facilitate the organizational operations in the most efficient way.

For example, one organizational unit might produce outputs and byproducts that impede the efficient functioning of another unit, such that no facility programmer would want a department that produces large amounts of harmful emissions next to the corporate cafeteria or an administrative unit with a large number of employees. Similarly, even in the age of electronic communication, we might need to promote face-to-face communication between corporate employees at different management levels or among those engaged in different processes. Depending on the nature of the organization, there might be a very strong requirement for personal communication and control that will presuppose departmental spatial adjacencies. On the other hand, particular departmental adjacencies might lead to sharing of facility and personnel or exploring new forms of collaboration and creating synergies. These are very difficult decisions to be made by client managers or management consultants. However, in the ideal programming case, such decisions should be facilitated by the programming team, provided that team has the necessary expertise and information.

\subsection{The Built Environment}

At this level, the built environment will be described in terms of overall organizational requirements, using a level of abstraction consistent with the overall organizational analysis. The requirements in many cases will be broad and open for interpretation so that they do not impose unnecessary restrictions on the consecutive levels of programming activity. It is not uncommon to reconsider business process organization or activity system restructuring in order to fit within existing physical environment and budget constraints. Although the initial cost of a facility is from $6 \%$ to $10 \%$ of the 30 -year lifecycle costs (Romm, 1994), very often this initial cost might be prohibitive for small and mid-size businesses or civic organizations. In such cases, in order to obtain the best fit possible among all aspects of the project situation, programmers might engage in cyclical reconsiderations and revisions of their programing decisions.

\section{The Departmental/Team/Group Level}

This level falls between those of the organization and the individual. It may be subdivided into layers if necessary, depending on the type and structure of the organization, the size of the 
department, and the diversity of operating units (Burton, et al., 2006; McLean, 2006). Its potential division is also a matter of the analytical precision required. Presently, we hone in on the team or group (depending on the organizational type) as the focus of our analysis. Small groups and teams deserve special attention because they are the links between highly formalized entities like the organization with the level of the human individual.

\subsection{The Agents at This Level}

The organization can be viewed as the environment of the department. The department might be organized in smaller units like teams (McLean, 2006). In projects with organized and structured work, it is important to review the team's goals and functions vis-a-vis the department (Burton, et al., 2006). The logic of inquiry and design is similar to the development of the teleological structure of the organization, but adapted to this smaller scale and the nature of the department and team.

In formal organizations, the group can be conceptualized as a team, task force, or goal-directed functional unit (McLean, 2006; Kinicki, 2018). It is a system of roles, or co-operative positions. Such a group may have both formal and informal structures. If they are institutionalized and codified, then the group is "formal." Each participant simultaneously enters these structures and functions both as a role-performer and as an individual/personality. For the normal existence of the group and for its efficient functioning is it important to keep a particular degree of demarcation between the formal and the informal (Harrington \& Fine, 2000; Markovsky, 2010; Michelson, 1988; Poole \& Hollingshead, 2005).

For the purposes of facility programming, we will conceptualize the small group as an organization of collective or collaborative activities. We also look at it as an organization of a small number of individuals that mediates the participation of the individual in larger social entities like the department (Michelson, 1988). In programming, it is important to differentiate between formal and informal groups (Michelson, 1988). This also takes into account the informal structures and the corresponding processes in the formal groups. Face-to-face communication is a major factor in creating group cohesion and in moderating the group's dynamics (Markovsky, 2010; Poole \& Hollingshead, 2005). While team analysis is quite formalized, the study of the informal structures of the team requires attention and reference to the knowledge base of social psychology and small group theory. In this regard, we primarily discuss the small group because of the need to understand small group processes in order to provide efficient group functioning and teamwork.

This intermediary level allows for more specific and human-centered analyses. Programmers will consider the roles and types of employees and customers, their demographics, education, professional culture, and ways of interacting. When customers/clients/patrons are serviced in cluster formations, as by some entertainment or civic organizations, the client group structure and process analysis becomes a complimentary line of inquiry. Meanwhile, as shown below, customers will be studied in greater detail at the individual level in order to design the proper interaction structures and activity systems.

The articulation of the universe of agent entities in terms of departments, teams, and small groups is bent towards organizational analysis. While organizational analysis approaches create the best framework for starting and directing programmatic action, there are other social phenomena that need to be considered at this level. There are a multitude of situations where individuals with 
different organizational affiliations and social roles interact with each other in recurrent patterns of action in order to engage in social exchanges. Most often these are service or entertainment environments, but this also happens very often in work environments.

For such situations, we suggest using Barker's concept of "behavior setting" (1963;1968), which refers to a system of standing or reoccurring patterns of behavior imbedded in and aligned with an invariable social and spatial environment (milieu). It also helps account for interaction locales where recurrent patterns of exchange occur. The agents in such behavior settings are conceptualized as the behavior setting populations (Barker, 1968) and might belong to one small group or to very different groups. In order to analyze such situations with our framework, we use the same articulation and analytical approach as shown in Table 1. In the Agent component, we distinguish different types of agents by their roles in the process of exchange. The behavior settings can also be conceptualized as functional settings in order to analyze these within the current framework and relate them to departmental and team structures as needed. Space limitations require that we elaborate possible applications of behavior setting theory in another paper.

\subsection{The Teleological Component}

Typically, departmental goals and objectives are defined and recorded (Buchanan, 1992). However, because of the different possible ways of organizing a corporation, department goals and functions need to be reviewed and confirmed during the programming process. Similarly, programmers might also have to do more work when they start investigating the teleology of teams and small groups.

The teleologies of formal groups or teams are more or less explicated either in departmental documents or in different kinds of policies. The teleology of informal groups and the informal behaviors occurring in formal groups are usually implicit and might need to be explicated in the programing process. The need to explicate and or redefine the teleological aspects of teams and small groups might not be as pronounced as it is with the organization as a whole. At this level, the teleology of the agent entity is more or less intertwined with the activity analysis that follows in the next section. In behavioral settings, participants with the same role might have the same teleology. However, different roles in the interaction and exchange processes presuppose different value systems and teleologies.

When researching behavior settings, with multiple participants acting like autonomous agents, it is more important to understand an agent's motivation for participating in the behavior setting, the particular role they play in that setting, and their objectives in this participation (Popov \& Chompalov, 2012). In some ways, this analysis bridges the group level with the individual level. The behavior setting analysis is different from the group or team action analysis because of the stronger emphasis on the individual agent as representative of a participation role or demographic group.

\subsection{Activities}

At the group level and/or behavior setting level, the most important aspect of understanding activities and shaping programmatic research is about interaction between activities and between 
agents. Agents might be collaborators or participants in exchanges. In all cases, there will be interaction and communication. The collaboration aspect fosters a somewhat different analysis than the exchange aspect, but these aspects are complimentary. Following the systems approach, when activities are functionally related, we conceptualize them as forming an activity system (Bedny \& Karwowski, 2007; Holt \& Morris, 1993; Tobach, 1999). The functional relationships can be articulated in several scales and aspects. Activity systems also need spatial and temporal coordination of their constituting activities so that they are physically possible and feasible.

At this group level of researching activity, the analytical units are molar rather than molecular. We use terminology supported by Kuutti (1999). Molar units are larger, self-sufficient and holistic. Molecular units are constitutive components of the molar entities. Molar units have autonomous existence with the system of activities and their boundaries are defined by their transactional characteristics, mostly by inputs and outputs. Through the input and output contact points, activities are assembled in systems, thus creating larger functional units and entities (Blackler, 1993; Blackler, Crump \& Mcdonald, 2000). This assemblage allows for a constant flow of people, materials, energy, and information, thus making the activity system a defined and outlined functional unit that connects and exchanges inputs and outputs with other activity systems at its level of functional importance for the department or organizations (Holt \& Morris, 1993; Blackler, 1993; Blackler, Crump \& Mcdonald, 2000).

In order to understand the activity systems, it is important to understand the content of the constituting activities in relation to their function, contributions to the system, inputs and outputs, and interactions and transactions with other system activities (Hewitt \& Shulman, 2011; Kuutti, 1999). Function is one such important concept. Functional analysis unveils collaborative and cooperative relationships among activities and is an important step to understanding their coordination and organization within the system. Functional analysis also involves the detection of conflicts that will impede exchanges between different activities (Kuutti, 1999).

This functional conceptualization implies the need for understanding the flow of agents, materials, energy, and information among the activities in the system, just as at the organizational level (Becker, Kugeler \& Rosemann, 2003; Keuning, 2007). However, now the analysis is more finegrained, focused on smaller, but still autonomous and well-delineated activities that have their own goal structure and results. The agents or participants in the group or behavior setting processes need to coordinate flows of actions in space and time in order to make them possible (Tobach, 1999). This coordination becomes the keystone of activity analysis at the group level. Without coordination, group activities will become a hilarious jumble and will foster competition for and conflict over resources, with the end result that there will be no possibility for meaningful interaction and the results of the activities will be unusable.

Activities can be categorized/typologized by the nature of their content and then studied in detail in order to develop the theoretical foundations for project-specific programming research (Popov \& Goza, 2016; 2018). Such a theoretical repository will help programmers start their investigation from a "higher" ground. The number of activity types is enormous, but still we can begin with the most common types and invest our scholarly resources there. When categorizing activities, it is important to consider the need for prioritization in order to organize more efficiently the activity system and to more efficiently distribute limited resources. We can talk about main and support 
activities, or primary and secondary, or instrumental and service activities. In all of these conceptualizations, there is an implied assumption that some activities are more important than others are. Even when we talk about instrumental activities, there might still be a need to differentiate them according to their importance for the functioning of the system (Popov \& Goza, 2016; 2018).

Activity systems involve interactions among their constitutive components that require considerations about activity goals, structure, resources, products, emissions, effects on other activities, and infringements incurred by other activities. These are the main dimensions of activities' interactions and corresponding relationships. They can be categorized in several groups: cooperative and synergistic, complementary and symbiotic, successive or parallel, competitive and conflicting, compatible or incompatible, autonomous or interdependent, and so forth (Popov \& Goza 2016; 2018). These dimensions of activities influence their interaction between themselves and with the built environment, and as a result they impact the organization of activity systems and the built environment. It is important to consider that the spatial relationships strongly impact activity configurations because the built environment is an important resource. It affects the flow of people and information, as well as the number of agents and materials that can be accommodated within the boundaries of the environment.

In the process of managing these relationships, some problems are resolved while others emerge. The emerging problems indicate new relationships that also need to be managed. Each reconfiguration of activity systems leads to changes in constituent activities, their relationships, and their relation to the built environment. This in turn leads to major changes in the necessary conditions. The new activity systems interact with each other and the built environment, thus triggering a new cycle of adaptation and alignment. It is a constant spiral: when an activity system is redesigned, it changes how it affects the "neighboring" activity systems. This in turn leads to changes in the sociospatial relationships "across the board." The adaptation and fitting together is a process that continues until a certain level of congruence among all components is achieved. Considering the "decent work" movement, it is very important to align activities not only for operational purposes, but also for supporting human wellbeing and satisfaction (Ferraro, Pais \& Dos Santos, 2015).

Planners in the manufacturing or highly formalized service industries have developed customized frameworks for process analysis. In those areas conceptualization and terminology are specifically developed for business process management and operations improvement. These are very precise methodologies that may or may not be applicable to the programming of civic and community buildings. In those organizational and building types, activities are not that strictly formalized and therefore allow for numerous variations depending on the free will of the agents, their motivation, and contingencies. Such frameworks and methodologies are used mostly by industrial engineers.

In programming research, the group level activity component requires the most attention. The activity analysis of departmental, team, group, or behavior settings require both breadth and depth. At this research stage, Activity Theory and systems thinking provide the methodological foundations for preparing ad hoc models for data collection and analysis. While it is very important to have theoretical support and shared research experience, each facility programming project is 
different and requires adaptation of existing knowledge, as well as methodological erudition and proficiency to deal with the idiosyncrasies that emerge.

\subsection{Necessary Conditions}

The articulation of activities and the analysis of activity components is a prerequisite for researching the conditions necessary to support them. These conditions can also be called activity needs, or needs that emerge in the process of activity. In this respect, these types of needs are different from the basic human needs discussed by the psychology of motivation, although they could be related depending on the specific activity setting and the agents' situation. The explication of necessary conditions is an essential step towards the formulation of design requirements, which will be discussed in the next section.

The articulation of necessary conditions is based on the notion that agents in pursuit of their goals and objectives engage in instrumental activities, and in this process the agents need particular social and environmental conditions (Popov \& Goza, 2016; 2018). In short, we can refer to these phenomena as necessary conditions or needs. The concept of necessary conditions is broader than the concept of needs and refers to both agents and the activity processes in which they participate. The main purpose of facility programming is to identify these necessary conditions and to translate them into design requirements. The necessary conditions will also be translated into criteria for evaluating each design solution and the project as a whole.

Activities take place in space and time. The flows of people, materials, energy, and information need to be facilitated and supported. It is necessary to optimize the interfaces among these flows, connections and exchanges. This will minimize the waste of resources and will maximize efficiency in collaborative and cooperative actions. Such considerations lead to examining the volumes of these flows and grouping activities together in space (Popov \& Goza, 2018). This analytical approach leads to the concepts of adjacency and proximity, which are essential in space planning. The intensity of exchanges among activities predetermines the necessity for adjacency and proximity.

Temporal synchronization is another important condition that needs to be provided and supported. It is as important as spatial adjacency because the passage of time is in one direction only and any disconnect between activity inputs and outputs will break the whole system of collaboration and cooperation, thus rendering the activity system dysfunctional and useless (Popov \& Goza, 2016). The temporal aspect is exceptionally important when it is necessary to synchronize flows of people, energy, and information. When these flows are separated in space, it is still possible to coordinate and connect them through technical means, although this would cost both time and resources. However, if there is no temporal coordination, the exchange will be disrupted and the outputs useless as the system of actions and activity components will break down and become a cluster of meaningless efforts. The synchronization of the beginning, the duration, the end, and the order of activities is essential to procuring an efficient system. Synchronization makes the system manageable and productive. 


\section{$5.5 \quad$ Built Environment}

At this stage, it is possible to move from abstract relationships and concepts like mission, goals, and strategies to a more specific teleological system of all agents involved, as well as to a detailed analysis of activities and necessary conditions. This stage is also the programming core as it provides the most important information for architectural decision making.

In programming, the built environment can be presented as design patterns, design guidelines, prescriptive requirements, and functional requirements. In most cases, programmers employ all of these options, and as needed, they might use additional materials. Our framework will provide directions for presenting the built environment predominantly in terms of functional requirements, but also as related background information. The connections among architectural decisions and the organizational concepts of higher level abstractions are intangible and difficult to materialize. When we move at the level of activity systems, behavior settings, team spaces, and group interaction areas, there is a practical possibility to collect detailed information and to develop requirements that can both guide architectural decision making and serve as criteria for project evaluation. At this level, programmers will describe the built environment as a system of intermediate scale design requirements. An intermediate scale of this type can range from a suite of adjacent spaces to a single team or group space.

\section{$6 \quad$ Individual Level}

The most immediate sociospatial interactions happen at the individual level. Individual humans interact with each other and the built environment, as they make ad hoc decisions and engage in contingent actions. They are directly influenced by the spatial environment and by other individuals near to them. In the end, the human individual (agent, co-worker, group member) is the end user, not the organization.

\subsection{The Agent}

Several facets of the human individual are presented, the: anthropometric, physiological, psychological, social-psychological, social, and cultural (Elbert, Kroemer \& Hoffman, 2018; Bechtel \& Churchman, 2002; Kroemer, Kroemer \& Kroemer-Elbert, 2010). This allows us to relate the analytical structure of the Agent to existing disciplines so that we may borrow knowledge and research methods from those fields.

The anthropometric facet. Human body size is the foundation of any consideration about the sizing of building spaces. In this regard, people are viewed as physical bodies with a particular configuration, size, volume, and weight. Depending on the design situation, these aspects of the human individual could become the basis for sizing the artificial environment, (Elbert, Kroemer \& Hoffman, 2018; Panero \& Zelnik, 1979).

The physiological facet. The human individual may also be viewed as an organism that exists by successfully adapting its physiological processes to external environment. These processes require exacting conditions (e.g., climate, acoustics, lighting) as physiology dictates the 
parameters of the ambient environment, meaning that a good microclimate is indispensable for supporting high productivity and keeping users healthy (Elbert, Kroemer \& Hoffman, 2018).

The psychological facet. The psychological realm is a hierarchical system, segmented into several levels and facets. Psychological levels range from psycho-physiological processes and phenomena which serve as a basis for the ensuing states, to the level of personality which serves as an integrating and directing core (Bechtel \& Churchman, 2002). An important area to study within this facet is the emotional world of the individual.

The social-psychological facet. This is about the study of interpersonal interaction and includes the individual's need to control the input and output of information (privacy), to protect his/her territorial rights, to sustain and communicate personal identity and social status, to voluntarily enter and exit the interaction, and to choose the intensity of physical contacts and the ensuing psychological relations (Bechtel \& Churchman, 2002). This facet of human existence is a domain that has a significant role in environmental design.

The social/sociological attributes of the individual. Analyzing and using the social attributes of the individual for programming purposes provides important information as these attributes often correlate with individual behavioral reactions, activity stereotypes and patterns, lifestyle, value system, and the hierarchy of priorities and goals (Bechtel \& Churchman, 2002; Michelson, 1988; Rapoport, 2005). Programmers need to know the sociological descriptions of building users in order to adapt to possible personas and scenarios. The social attributes of the individual, together with the cultural aspects provide a holistic picture of a particular group of building users.

The cultural attributes of the individual. Environmental interactions are strongly influenced by the cultural background of the individual. Collective culture resides in the individual and shapes such core elements as world view, beliefs, values and norms, images and schemata, behavioral stereotypes, and lifestyle (Hofstede, Hofstede \& Minkov, 2010; Rapoport, 2005). Knowledge about the specific contents of each of these elements is an important prerequisite for the organization of space for human action and interaction and for providing comfort and satisfaction within that space.

\subsection{Goals}

Activity theory conceptualizes human beings as conscious actors, or agents that formulate goals. Agents achieve these goals through a series of activities, and experience the need for some conditions in the process of these activities. User goals are concepts about what the agent strives to achieve. Agents construct a system of activities in order to achieve their goals. Goals are operationalized in strategies and activities. Strategies are general programs of action and deployment of resources used to attain comprehensive objectives. Individual goals are teleological conceptualizations about what is to be achieved or acquired by the person. Goals guide the selection and organization of actions (Hitt, Miller \& Colella, 2015; Robbins, 2003; Wade, 1977). Goals advise the individual to establish priorities, organize resources, and carry out activities over extended periods of time (Robbins, 2003). The goals not only presuppose the choice of activity, but also the choice of a way or method to do this activity. Researching and unveiling individual user 
goals and objectives is very important for analyzing and constructing activities at the individual level (Wilson et al., 2012).

Hierarchy of needs theories (Maslow, 1989) and the role of motivation for setting individual goals are very informative for predicting personal goal-setting and hierarchically ranking desired objectives when examining individual behavior in the built environment. The individual level of goal-setting is important because most of the environmental interactions take place at the individual level. Personal goals drive individual activity (Wilson et al., 2012) and in this way affect the environmental requirements of the individual. Individuals set goals and objectives in a range from short-term to long-term. The immediacy of the goal is important when individuals have to make compromises and trade-offs when the environmental resources force them to prioritize actions, comfort, and convenience.

\subsection{Individual activities}

At the individual level, we can observe and study the most immediate sociospatial interactions. Activity is the major linking mechanism between the social and the spatial. Individual activity mediates interaction in several aspects (Popov \& Goza, 2016; 2018). The complexity of activity requires that programming researchers consider several other aspects and ways to understand individual activity.

One way to look at this mediation and the ensuing relationships is to refer to the structure of the human individual, presented above. In this way, we can differentiate several levels, starting with the anthropometric, going to the physiological, psychophysiological, psychological, social psychological, social, and cultural levels (or aspects). Regarding programmatic research, it is important to remember all these levels or aspects when we explore the actions and activities of the individual in the built environment (Lang \& Moleski, 2010). This is essential for undertaking research in a holistic and exhaustive way and to recognize how an individual's needs emerge in the process of activity.

Programmers should also consider examining the importance of content as it relates to the study of individual activity (Barker, 1963; 1968). The content approach is based on the perception and conceptualization of activity components that are functionally complete and identifiable. These components display strong thematic distinctiveness. They can be recognized and articulated. The content of an activity component is most often described by its function in the activity system. The completeness of the component is defined by its inputs and outputs. The output can also be seen as the function or contribution of the component to the larger system. Many activity components are referred to by the name of their content. In most cases, this is expressed as a verb.

\subsection{Necessary conditions}

The delineation of necessary conditions or needs is the end purpose of programmatic user research. A necessary condition or need may be experienced by the individual as a deficit or discrepancy. Under certain conditions it is conceptualized as a problem. Problem seeking is one possible programming strategy (Pena \& Parshall, 2001). A complimentary perspective is to view necessary conditions as resources that will support the individual in the process of activity. 
Regardless of perspective, activities are examined with the objective of discovering emerging needs and necessary conditions.

As mentioned above, most environmental interactions take place at the individual level and are predominantly driven by anthropometrics and physiological needs. If the individual needs for physical clearances and room temperature are not met, users cannot function in that space. If a space does not conform to the basic anthropometric and biodynamic requirements of the user, the activity performance is severely curtailed or even blocked (Lang \& Moleski, 2010). This is most obvious when there is direct contact between material objects and the human body, such as shoes, chairs, and stairs. If a space is too narrow to contain a desired number of persons, then all design considerations regarding human interests, activity patterns, and preferences become irrelevant, because the spatial constraints diminish the productivity and even the feasibility of a particular human activity (Panero \& Zelnik, 1979).

When discussing individual level requirements within this framework, it is important to consider the hierarchy of needs (Koltko-Rivera, 2006; Maslow, 1989) and its role in understanding individual requirements regarding the built environment. This involves considerations about the relations between the levels of organization, the importance of needs at each level, and the tolerance to unsatisfied needs in relation to the functioning of the whole system.

Usually, but not always, satisfying the needs of each lower level of organization is critical before proceeding to satisfy the needs of the higher level. Conversely, each higher level predetermines to a large extent the ways the needs of the lower levels are shaped, the appropriate means for their satisfaction, and possible side effects. In cases where people must suppress unsatisfied lower level needs to continue functioning at a higher level, the cost may be discomfort and strain (KoltkoRivera, 2006). There is a critical threshold beyond which tolerance is either not feasible or impossible. While long-term and life goals influence the life trajectory of the individual (Little, Salmela-Aro \& Phillips, 2007), the short-term objectives have a stronger influence on environment. From the hierarchy of needs perspective, higher needs more strongly affect the symbolic aspects of the built environment (Turner, 2014; Van Marrewijk \& Yanow, 2010), while the lower level needs work in an almost deterministic way regarding the provisions of necessary conditions.

\subsection{Built Environment}

When programming, we have to consider two groups of categories for describing the built environment. The conventional analytical categories describing the built environment are primarily used as reference points for guiding the outcomes of user research. This is accomplished through constant awareness to analytically describing how the built environment guides the transition from necessary conditions to design requirements. The systems of user requirements that programmers develop are programmatic descriptions of the built environment (Popov \& Goza, 2018). The programmatic instruments for describing the built environment include several different categories: design requirements, constraints, considerations, guidelines, and design patterns (Popov \& Goza, 2018).

At the individual level of research and analysis, the variety of design requirements can be structured according to the aspects and structures of the individual presented above. Specifically, the anthropometrics drive particular spatial dimensions in a very deterministic way, while the 
physiology of the individual presupposes ambient conditions within a very narrow margin of variance. However, at the psychological and social psychological levels, the environmental relationships are probabilistic, with unpredictable outcomes. Lastly, the symbolic and aesthetic description of the built environment at individual level provide an important foundation for decision making during the design process (Turner, 2014; Van Marrewijk \& Yanow, 2010).

\section{$7 \quad$ Concluding Remarks}

This study both developed and presented a framework designed to enable scholars of the facility programming cognitive domain to more easily handle the extremely large amounts of information they typically utilize, to guide the development of their research designs and procedures, and to suggest process structure. The development of this framework was informed by both Activity Theory and Systems Theory. The resultant framework synthesizes knowledge about the most important aspects and layers of the sociospatial realm and articulates the analytical clusters that can be used as guides for developing programmatic research designs. The matrix created presents information about each component, emphasizing the facets that are most important for exploring sociospatial structures and relationships. The "horizontal" axis of the framework is based on an activity model that consists of agents, their goals, activities, necessary conditions, and the built environment that provides these conditions. The "vertical" axis brings in the three levels or scales for analyzing the social realm (from organization to groups to individuals).

Each component or matrix cell provides information that can be used to develop sensitizing concepts and guidelines for developing customized programmatic research designs and instruments. The framework is general enough to cover a wide variety of building types and programming situations. It is also flexible enough to be developed in multiple ways, including adding additional detail, even to the level of a major guidebook, as it contributes to facility programming theory. Each component can be developed and adapted in additional detail to fit the needs of particular organizational and building types. Specially, this framework is designed to be adapted and operationalized to include the particulars of all projects and building types because the best guiding framework is always a customized one and because the sociospatial world is much more complicated than a simple sequence of levels and structures.

In our earlier study (Popov \& Goza, 2018), we developed the methodological principles for creating frameworks to guide the collection of programming information. In this study we showed how those methodological principles work and developed a general framework. The completion of this study has brought us to the third part of this project. Specifically, the next stage of this project will use the framework presented in this study to develop a generic model of the data collection process that delineates process steps, their sequence, and their content. The intent of the process model will be to provide ideas on how to use this framework in field research, as well as to provide the process with both structure and content. The proposed approach will produce better information to support decision making throughout the design process as well as possible options for the further operationalization of the framework in terms of content and process structure. 


\section{$8 \quad$ References}

BAILEY, K. (1994). Sociology and the New Systems Theory. Albany, NY: State University of New York Press. https://doi.org/10.1007/0-387-36274-6_19

BAILEY, K. (2001). Systems theory. In J. Turner, (Ed.), Handbook of Sociological Theory, pp.379-401. New York, NY: Springer. https://doi.org/10.1007/0-387-36274-6_19

BANATHY, B. (1996). Designing Social Systems in a Changing World. New York, NY: Springer. DOI: https://doi.org/10.1007/978-1-4757-9981-1

BARKER, R. (1963). On the nature of the environment. Journal of Social Issues, Vol. 19, No. 4, pp.17-38. https://doi.org/10.1111/j.1540-4560.1963.tb00456.x

BARKER, R. (1968). Ecological Psychology: Concepts and Methods for Studying the Environment of Human Behavior. Stanford, CA: Stanford University Press.

BAUSCH, K. (2001) The Emerging Consensus in Social Systems Theory. New York, NY: Kluwer Academic/Plenum Publishers. https://doi.org/10.1007/978-1-4615-1263-9

BECKER, J., KUGELER, M. and ROSEMANN, M. (Eds.) (2003). Process Management: A Guide for the Design of Business Processes. New York, NY: Springer. https://doi.org/10.1007/978-3-540-24798-2

BECHTEL, R. and CHURCHMAN, A. (Eds.) (2002). Handbook of Environmental Psychology. New York, NY: John Wiley \& Sons.

BEDNY, G. and KARWOWSKI, W. (2007). A Systemic-Structural Theory of Activity: Applications to Human Performance and Work Design. Boca Raton, FL: CRC Press/Taylor and Francis. https://doi.org/10.1201/9781420009743

BLACKLER, F. (1993). Knowledge and the theory of organizations: Organizations as activity systems and the reframing of management. Journal of Management Studies, Vol. 30, No. 6, pp. 863-884. https://doi.org/10.1111/j.1467-6486.1993.tb00470.x

BLACKLER, F., CRUMP, N. and MCDONALD, S. (2000). Organizing processes in complex activity networks. Organization, Vol. 7, No. 2, pp. 277-301. https://doi.org/10.1177/135050840072005

BLUMER, H. (1954). What is wrong with social theory? American Sociological Review, Vol.19, No. 1, pp. 310. DOI: $10.2307 / 2088165$

BORKOWSKI, N. (2015). Organizational behavior, Theory, and Design in Health Care. Burlington, MA: Jones and Bartlett Publishers.

BRANNICK, M. T., LEVINE, E. L. and MORGESON, F. P. (2007). Job and Work Analysis: Methods, Research, and Applications for Human Resource Management, 2nd ed. Los Angeles, CA: SAGE Publications. http://dx.doi.org/10.4135/9781483329505

BUCHANAN, L. (1992). Vertical trade relationships: The role of dependence and symmetry in attaining organizational goals. Journal of Marketing Research, Vol. 29, No. 1, pp. 65-75. https://doi.org/10.1177/002224379202900106 
BURKE, W. (2014). Organization Change: Theory and Practice, 4th ed. Thousand Oaks, CA: SAGE.

BURTON, R., ERIKSEN, B., HÅKONSSON, D. and SNOW, C. (2006). (Eds.). Organizational design: A step-by-step approach. New York, NY: Springer.

CAMERON, K. S. and QUINN, R. E. (2011). Diagnosing and Changing Organizational Culture: Based on the Competing Values Framework, 3rd ed. San Francisco, CA: Jossey-Bass.

CHERRY, E. (1999). Programming for Design: From Theory to Practice. New York, NY: John Wiley.

CUMMINGS, T. and WORLEY, C. (2008). Organizational Development and Change, 9th ed. Mason, OH: South-Western College Publ.

DAVIS, G. and SZIGETI, F. (1979). Functional and technical programming: When the owner/sponsor is a large or complex organization. In Proceedings of the Fourth International Architectural Psychology Conference. Louvaine-la-Neuve, July 10-14, 1979.

DUERK, D. (1993). Architectural Programming: Information Management for Design. New York, NY: Van Nostrand Reinold.

ELBERT, K., KROEMER, H. and HOFFMAN, A. (2018). Ergonomics: How to Design for Ease and Efficiency, 3rd ed. London, UK: Elsevier Academic Press.

ENGeStrom, Y., MietTINEN, R. and PUNAMAKI, R. (Eds.). (1999). Perspectives on Activity Theory. Cambridge, UK: Cambridge University Press. https://doi.org/10.1017/CBO9780511812774

FARARO, T. J. (2001). Social Action Systems: Foundation and Synthesis in Sociological Theory. Westport, CT: Praeger.

FERRARO, T., PAIS, L. and DOS SANTOS, N. (2015). Decent work: An aim for all made by all. International Journal of Social Sciences, Vol. 4, No. 3, pp. 30-42. DOI: 10.20472/SS2015.4.3.003

FREEMAN, R., HARRISON, J., WICKS, A., PARMAR, B. and DE COLLE, S. (2010). Stakeholder Theory: The State of the Art. Cambridge, UK: Cambridge University Press. https://doi.org/10.1017/CBO9780511815768

GLASER, B. G. and STRAUSS, A. L. (1967). The Discovery of Grounded Theory: Strategies for Qualitative Research, 1st ed. New Brunswick: Aldine. E-book at https://doi.org/10.4324/9780203793206

HARRINGTON, B. and FINE, A. (2000). Opening the "black box": Small groups and twenty-first century sociology, Social Psychology Quarterly, Vol. 63, No. 4, pp. 312-324. https://doi.org/10.2307/2695842

HENDRICK, H. W. and KLEINER, B. (Eds.). (2005). Macroergonomics: Theory, Methods, and Applications. Boca Raton, FL: CRC Press.

HERSHBERGER, R. (2015). Architectural Programming and Predesign Manager. New York, NY: Routledge. https://doi.org/10.4324/9781315645728

HEWITT, J. and SHULMAN, D. (2011). Self and society: A symbolic interactionist social psychology, 11th ed. Boston, MA: Allyn \& Bacon.

HITT, M, MILLER, C. and COLELLA, A. (2015). Organizational Behavior, 4th ed. New York, NY: Wiley. HOFSTEDE, G., HOFSTEDE, G.J. and MINKOV, M. (2010). Cultures and Organizations: Software of the 
Mind, 3rd ed. New York: McGraw-Hill.

HOLT, G.R. and MORRIS, A.W. (1993). Activity theory and the analysis of organizations. Human Organization, Vol. 52, No. 1, pp. 97-109. https://doi.org/10.17730/humo.52.1.u305r18277724374

JABAREEN, Y. (2009). Building a conceptual framework: Philosophy, definitions, and procedure. International Journal of Qualitative Methods, Vol. 8, No. 4, pp. 49-62. https://doi.org/10.1177/160940690900800406

JACKSON, M. (2000). Systems approaches to management. New York, NY: Springer. https://doi.org/10.1007/b100327

KAPTELININ, V., KUUTTI, K. and BANNON, L. (1995). Activity theory: Basic concepts and applications. In B. Blumenthal, B., Gornostaev, J. and Unger C. (Eds.), Human-computer interaction, pp. 189-201. New York, NY: Springer. https://doi.org/10.1007/3-540-60614-9_14

KROEMER, K., KROEMER, H. and KROEMER-ELBERT, K.E., 2010. Engineering Physiology: Bases of Human Factors Engineering/Ergonomics, 4th ed. New York, NY: Springer. https://doi.org/10.1007/978-3-642-12883-7

KEUNING, D. (2007). Management: A European Perspective, 3rd ed. London, New York: Routledge.

KINICKI, A. and WILLIAMS, B. (2018). Management: A Practical Introduction, 8th ed. New York, NY: McGraw-Hill Education.

KOLTKO-RIVERA, M. (2006). Rediscovering the later version of Maslow's hierarchy of needs: Selftranscendence and opportunities for theory, research, and unification. Review of General Psychology, Vol. 10, No. 4, pp. 302-317. DOI: 10.1037/1089-2680.10.4.302

KUUTTI, K. (1996). Activity Theory as a potential framework for Human-Computer Interaction research. In B. Nardi (Ed.), Context and Consciousness: Activity Theory and Human-Computer Interaction, pp. 17-44. Cambridge, MA: MIT Press.

KUUTTI, K. (1999). Activity theory, transformation of work, and information systems design. In Y. Engestrom, R. Miettinen and R. Punamaki (Eds.), Perspectives on Activity Theory, pp. 360-376. Cambridge, UK: Cambridge University Press. https://doi.org/10.1017/CBO9780511812774.024

LANG, J. and MOLESKI, W. (2010). Functionalism Revisited: Architectural Theory and Practice and the Behavioral Sciences. New York, NY: Routledge. https://doi.org/10.4324/9781315254838

LEKTORSKII, V.A. (Ed.). (1990). Activity: Theories, Methodology and Problems. Orlando, FL: Paul Deutsch Press, Inc.

LOFLAND, J. and LOFLAND, L. (1995). Analyzing Social Settings: A Guide to Qualitative Observation and Analysis, 3th ed. Belmont, CA: Wadsworth/Thomson Learning.

LUHMANN, N. (1995). Social systems, trans. J Bednarz, Stanford, CA: Stanford University Press.

LUHMANN, N. (2012). Introduction to systems theory, trans. P Gilgen, Cambridge, UK: Polity.

LITTLE, B., SALMELA-ARO, K. and PHILLIPS, S. (Eds.). (2007). Personal Project Pursuit: Goals, Action, and Human Flourishing. New York, NY: Taylor \& Francis, Psychology Press. https://doi.org/10.4324/9781315089928 
MCLEAN, G. (2006). Organization Development: Principles, Processes, Performance. San Francisco, CA: Berrett-Koehler Publishers.

MARKOVSKY, B. (2010). Modularizing small group theories in sociology. Small Group Research, Vol. 41, No. 6, pp. 664-687. https://doi.org/10.1177/1046496410367437

MASLOW, A. (1989). A theory of human motivation. In Leavitt, H., Pondy, L. and Boje, M. (Eds.), Readings in Managerial Psychology, 4th ed., pp. 20-35. Chicago, IL: The University of Chicago Press.

MICHELSON, W. (1988). Groups, aggregates and the environment. In Zube, E. and Moore, G. T. (Eds.), Advances in Environment, Behavior, and Design, Vol. 1, pp. 161-185, New York, NY: Plenum. https://doi.org/10.1007/978-1-4899-5345-2_7

PANERO, J. and ZELNIK, M. (1979). Human Dimension \& Interior Space: A Source Book of Design Reference Standards. New York, NY: Whitney Library of Design.

PENA, W. and PARSHALL, S. (2001). Problem Seeking: An Architectural Programming Primer, 4th ed. New York, NY: Wiley.

POOLE, S. and HOLLINGSHEAD, A. (Eds.). (2005). Theories of Small groups: Interdisciplinary Perspectives. Thousand Oaks, CA: SAGE Publications. https://doi.org/10.4135/9781483328935

POPOV, L. and CHOMPALOV, I. (2012). Crossing over: The interdisciplinary meaning of behavior setting theory. International Journal of Humanities and Social Science, Vol. 2, No. 19, pp.18-27.

POPOV, L. and GOZA, F. (2016). Towards a metatheoretical basis of an activity approach to architectural programming research. IAFOR Journal of Psychology and Behavioral Sciences, Vol. 2, No. 3, pp. 4761. https://doi.org/10.22492/ijpbs.2.3.04

POPOV, L. and GOZA, F. (2018). Philosophical foundations and metatheoretical considerations for creating frameworks to collect facility programming information. International Journal of Social Sciences, Vol. 7, No. 2, pp. 92-108. https://doi.org/10.20472/SS2018.7.2.005

PREISER, W.F.E. (Ed.). (1993). Professional Practice in Facility Programming. New York, NY: Van Nostrand Reinhold. https://doi.org/10.4324/9781315717012

PRENKERT, F. (2006) A theory of organizing informed by activity theory: The locus of paradox, sources of change, and challenge to management. Journal of Organizational Change Management, Vol. 19, No. 4, pp. 471-490. DOI 10.1108/09534810610676671

RAPOPORT, A. (2005). Culture, Architecture, and Design. Chicago, IL: Locke Science Pub. Co.

ROBINS, S. (2003). Essentials of organizational behavior, 7th ed. Upper Saddle River, NJ: Prentice Hall.

ROMM, J. (1994). Lean and Clean Management: How to Boost Profits and Productivity by Reducing Pollution. New York, NY: Kodansha International.

SAFWAT, A. (2015). Corporate social responsibility: Rewriting the relationship between business and society. International Journal of Social Sciences, Vol. 4, No. 1, pp. 87-99. DOI: 10.20472/SS2015.4.1.006 
ŠIKÝŘ, M., GOROKHOVA, A. and ŠAFRÁNKOVÁ, J. (2019). Opinions on managing postmillennials by management university students. International Journal of Social Sciences, Vol. 8, No. 1, pp. 43-54., DOI: 10.20472/SS.2019.8.1.004

STANFORD, N. (2007). Guide to Organisation Design: Creating High-Performing and Adaptable Enterprises. London: Profile Books Ltd.

TOBACH, E. (1999). Activity theory and the concept of integrative levels. In Y. Engestrom, R. Miettinen, and R. Punamaki (Eds.), Perspectives on activity theory, pp. 133-146. Cambridge, UK: Cambridge University Press. doi: 10.1017/CBO9780511812774.011

TURNER, B.A. (Ed.). (2014). Organizational Symbolism. Berlin; New York: Walter de Gruyter.

VAN MARREWIJK, A. and YANOW, D. (Eds.). (2010). Organizational Spaces: Rematerializing the Workaday World. Cheltenham, UK: Edward Elgar Publishing. https://doi.org/10.4337/9781849804912

WADE, J. (1977). Architecture, Problems, and Purposes: Architectural Design as a Basic Problem-Solving Process. New York, NY: Wiley.

WAPNER, S. (1987). A holistic, developmental, system-oriented environmental psychology: Some beginnings. In D. Stocols and I. Altman (Eds.), Handbook of Environmental Psychology, Vol. 2, pp. 1195-1226. New York, NY: John Wiley and Sons.

WILSON, M., BENNETT, W., GIBSON, S. and ALLIGER, G. (Eds.). (2012). The Handbook of Work Analysis: Methods, Systems, Applications and Science of Work Measurement in Organizations. New York, NY: Routledge. https://doi.org/10.4324/9780203136324 